\title{
The Investigation and Analysis of Urban Elderly Endowment Patterns and Endowment Demand
}

\author{
Fang Wang ${ }^{1, a^{*}}$, Entian Qie ${ }^{2, b}$ \\ ${ }^{1}$ School of Urban Construction, Wuhan University of Science and Technology, Wuhan 430000, \\ China; \\ ${ }^{2}$ School of Urban Construction, Wuhan University of Science and Technology, Wuhan 430000, \\ China. \\ a6978893@qq.com, b36696371@qq.com \\ ${ }^{*}$ The corresponding author
}

\begin{abstract}
Nowadays the degree of aged tendency of population in our country is high, the requirements of provide for the aged are growing day by day, the problems of provide for the aged has become an important social problem in China. Through comparative analysis to the advantages and disadvantages of three kinds of endowment modes in current, meanwhile take Wuhan as an example, through research analysis to the basic information of the urban elderly, living status and willingness, demand to community environment and facilities, put forward the conception of plan and construct a facilities for the elders combined with living, entertainments and activities, medical rehabilitation, and elaborate to the functions of the community endowment facilities, in order to promote the development of community endowment service.
\end{abstract}

Keywords: Aged tendency of population; Endowment patterns; Urban elderly; Endowment demand; Community endowment facilities

\section{城市老年人养老模式及养老需求调查分析 \\ 王芳 ${ }^{1}$ ，郄恩田 ${ }^{2}$}

(1. 武汉科技大学 城市建设学院, 湖北 武汉 430000; 2. 武汉科技大学 城市建设学院, 湖北 武汉 430000)

摘要：当前我国人口老龄化程度高, 养老需求日益增长, 养老问题已成为我国面临的重要社会问题。通过对比分析我 国现行的三种养老模式的优缺点，并以武汉市为例，对城市老年人的基本情况、居住现状与意愿以及对社区环境和设施的需 求调研分析，提出在居住小区规划建设集生活起居、活动娱乐、医疗康复功能为一体的养老设施的构想，并对社区养老设施 的功能定位进行阐述，以推进社区养老服务的发展。

关键词: 人口老龄化; 养老模式; 城市老年人; 养老需求; 社区养老设施

中图分类号：TU 025 文献标志码：A

引言

一些发达国家和地区的老龄化问题出现较早，经历了长时间的探索与研究，有一套完善的、专业的养 老服务体系。当前我国城市居住区的开发建设处在蓬勃发展期, 然而在社区养老设施的建设方面只是处于 起步阶段, 重视程度也还远远不够, 相关规范标准上对于普通社区的养老设施及外环境的规划设计方面并 没有明确而全面的要求。房地产开发商为了尽快收回投资获得最大利益, 对于居住区中收益较小的老年服 务设施配套修建不完善，造成我国现有已建成的居住社区中相关养老设施的建设仅停留在无障碍设计的基 
本层面 ${ }^{[1]}$ 。此外, 我国一般家庭目前均难以接受当今社会上服务质量较好的机构养老和养老社区的费用, 因此有必要探索适应我国发展需要的社区养老设施规划设计及实施策略。

\section{1 现行的主要养老模式分析}

我国现行的养老模式主要有传统的家庭养老、社会福利机构养老、商业社区养老三种 ${ }^{[2]}$ 。就为老年人 提供相应的生活环境方面，根据各种养老模式不同特征，分别对这三种类型进行探讨。

\section{1 传统的家庭养老}

家庭养老是一种建立在我国传统血亲价值基础上的养老模式，从老年人情感角度看，家庭养老模式更 符合中国老年人的意愿。老年人不愿离开自己长期熟悉的家庭和社区环境, 居住在自己家庭可以保持与家 庭成员和社区邻居最密切的联系。然而, 年轻子女工作压力加大, 难以有时间照顾老人, 这也导致家庭养 老模式已经难以适应当今的养老需要 ${ }^{[3]}$ 。

\section{2 社会福利机构养老}

福利性养老院由国家民政部门出资建设运营，居住的主要是生活特别困难的孤塞老人，或者是子女没 时间照顾但又特别需要照顾的老人，这些老人集中一起居住，工作人员为他们进行统一照顾，并提供相应 服务。在一定程度上来说, 这种方式救济了很多需要照顾的老人，也起到了人道主义的作用。但福利性养 老院往往由于经费不足，使得住房、医疗设施等环境较差，服务人员的服务技能普遍也缺少专业培训，难 以满足城市老年人的养老需求。

\section{3 商业社区养老}

近几年来，老龄化的发展使专供老年人居住的“养老社区”的开发建设掀起热潮，房地产开发企业， 保险、投资公司，酒店管理及相关服务管理企业等社会力量，都看到了养老地产的商机，纷纷投资开发老 年社区、老年公寓等。由此近年来开发了一大批老年社区、养老地产、养老公寓等, 如北京太阳城、上海 宝康老年公寓等。其选址上大多是在远离市中心的位置, 相关规划和配套设施比较完善, 但由于高额的收 费, 一般家庭难以支付其费用, 从而造成居住利用率也较低 ${ }^{[4]}$ 。

\section{2 城市老年人养老需求调研}

对我国城市老年人养老居住情况进行一次全面的调研是非常困难的, 因此本课题的调研对象主要来自 于武汉市某几个居住社区、养老院和公园里的老年人, 通过调研了解老年人的养老居住状况、养老意愿及 需求 ${ }^{[5]}$ 。

\section{1 调查目的与方法}

笔者于 2015 年 7 月, 以 “城市老年人养老情况调查” 进行问卷调查, 问卷涉及的内容包括老年人基 本情况、居住现状与意愿、对社区环境和设施的需求等。本次调研为抽样调查方式, 选取的调查地点为不 同类型的老年人聚集区, 且较为分散, 涉及 4 个社区、 2 个养老院与 1 个公园。期间通过与老年人交流得 出问卷情况, 同时考察调研所在地方的环境。通过采访 78 名老人, 最终得到有效问卷 62 份。另外, 也对 社区工作人员进行访谈, 了解社区的概况、老年人数量、结构层次、社区养老服务情况等 ${ }^{[6]}$ 。 


\section{2 调查对象基本情况}

在被调查的老年人中, 男性占 $54.8 \%$, 女性占 $45.2 \%$, 男女比例为: $1.2: 1$, 较为协调。按年龄段来进 行划分, $60 \sim 64$ 岁的老年人有 24 人, 占比例为 $38.7 \% ; 65^{\sim} 69$ 岁的老年人有 19 人, 占比例为 $30.6 \% ; 70^{\sim} 74$ 岁的老年人有 11 人, 占比例为 $17.7 \% ; 75^{\sim} 79$ 岁的老年人有 5 人, 占比例为 $8.1 \% ; 80$ 岁的老年人有 3 人, 占比例为 $4.8 \%$ 。

在身体状况方面, 完全能够自理的有 32 人, 基本能够自理的有 27 人, 不能自理的有 3 人。所调研的 老年人身体状况普遍较好, 调查到的自理能力较差的老人主要是养老院中居住的老人。

在收入方面, 老年人的月收入水平主要集中在 $1000^{\sim} 3000$ 元/月之间, 在武汉市的部分养老院调研中 得知, 条件稍好的养老院收费达到 3000 元/月以上, 老人普遍无法承担入住条件较好的养老机构的费用。

\section{3 居住现状及养老意愿}

受访的老年人现在的居住方式主要为与已婚子女同住, 占比例为 $48 \%$, 夫妻自住的比例为 $33 \%$, 与未 婚子女同住所占比例为 $7 \%$, 独居的比例为 $7 \%$ 。大多数与已婚子女同住的老人都是因为照顾小孩需要, 夫 妻自助的老人普遍身体状况较好, 能够自理日常生活, 其中很多是与子女家相邻较近。

为了了解老年人的理想养老意愿, 我们设置将老年人与子女的居住关系分为四种: 独自居住、子女同 住、紧邻子女、随便哪里都可以。另外将养老居住模式分为以下几种: 独居, 家中养老, 自己所在社区内 的养老, 社区外养老院、敬老院等机构 ${ }^{[7]}$, 郊区独立的老年社区, 其他。结果显示大部分老年人都是愿意 紧邻子女并希望在自己所在社区内养老或家中养老 (如图 1)。笔者认为, 这其中原因可能因为老年人害怕 孤独, 希望子女在身边, 得到大家庭的温暖, 也符合我国的传统价值观。

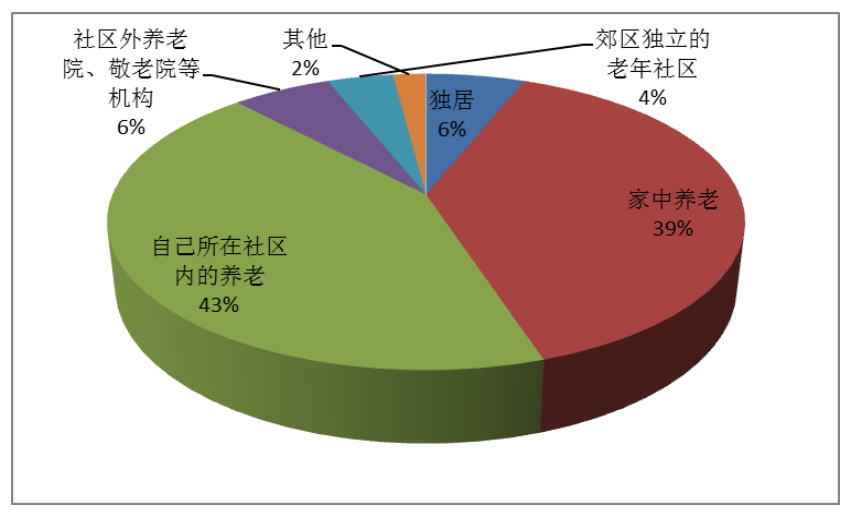

图 1 老年人理想中的养老居住模式

\section{4 对居住社区环境、设施与服务的需求}

为了了解现有社区环境在适老化方面存在的不足, 通过对社区户外环境改善需求调研中, 发现选择所 占比例从高到底依次为: 方便出行的坡道及路边扶手、休息座椅、步行道路及指向标志、绿化环境、小型 广场、夜间照明设施、遮阳挡雨设施 (如图 2)。在社区的调研中, 笔者发现普遍在无障碍设施方面考虑欠 佳, 老社区尤为明显, 对老年人出行造成不便。而对于希望未来社区能提供的服务设施方面, 医疗服务设 施、日常护理设施排在最前面, 虽然不少社区均有医疗诊所, 但其对老年人的针对性较差。受访的老年人 对老年健身活动设施、公共活动中心、休闲娱乐设施也有强烈的需求 (如图 3)。 


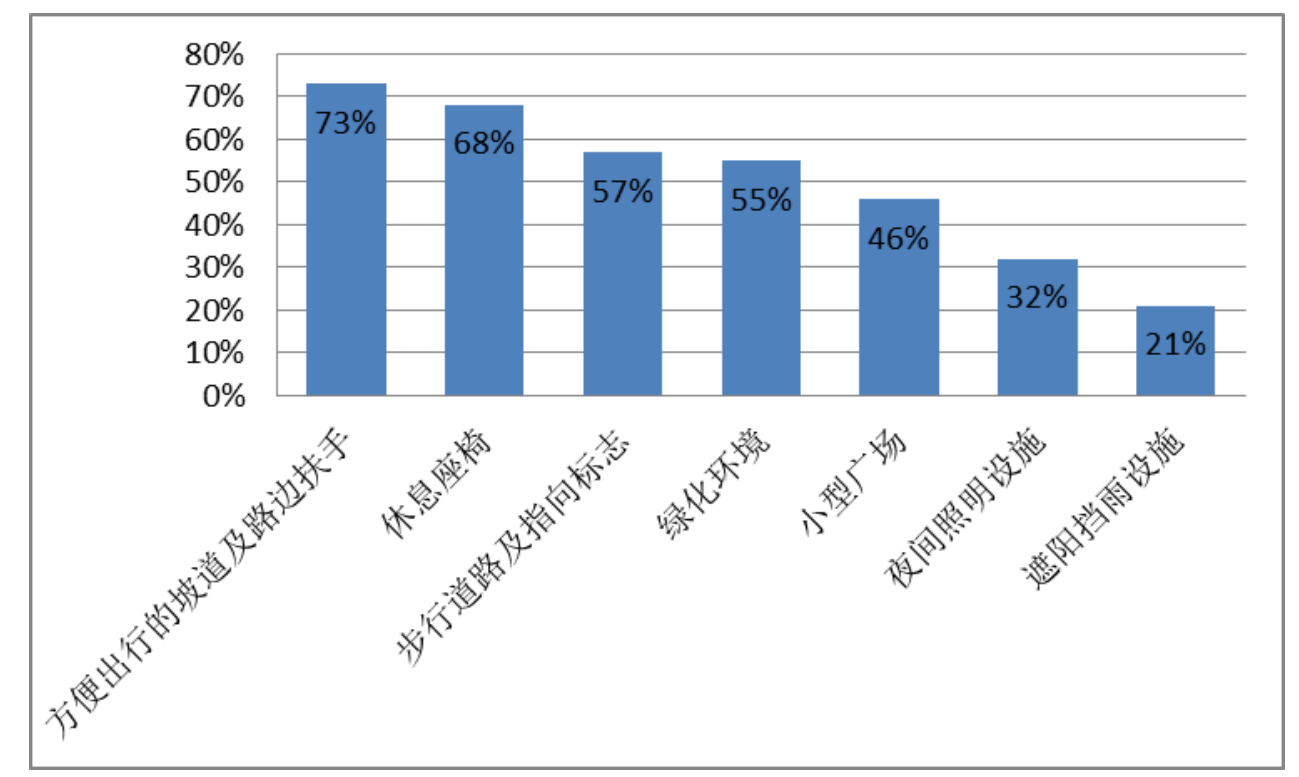

图 2 老年人对现有社区户外环境改善需求情况

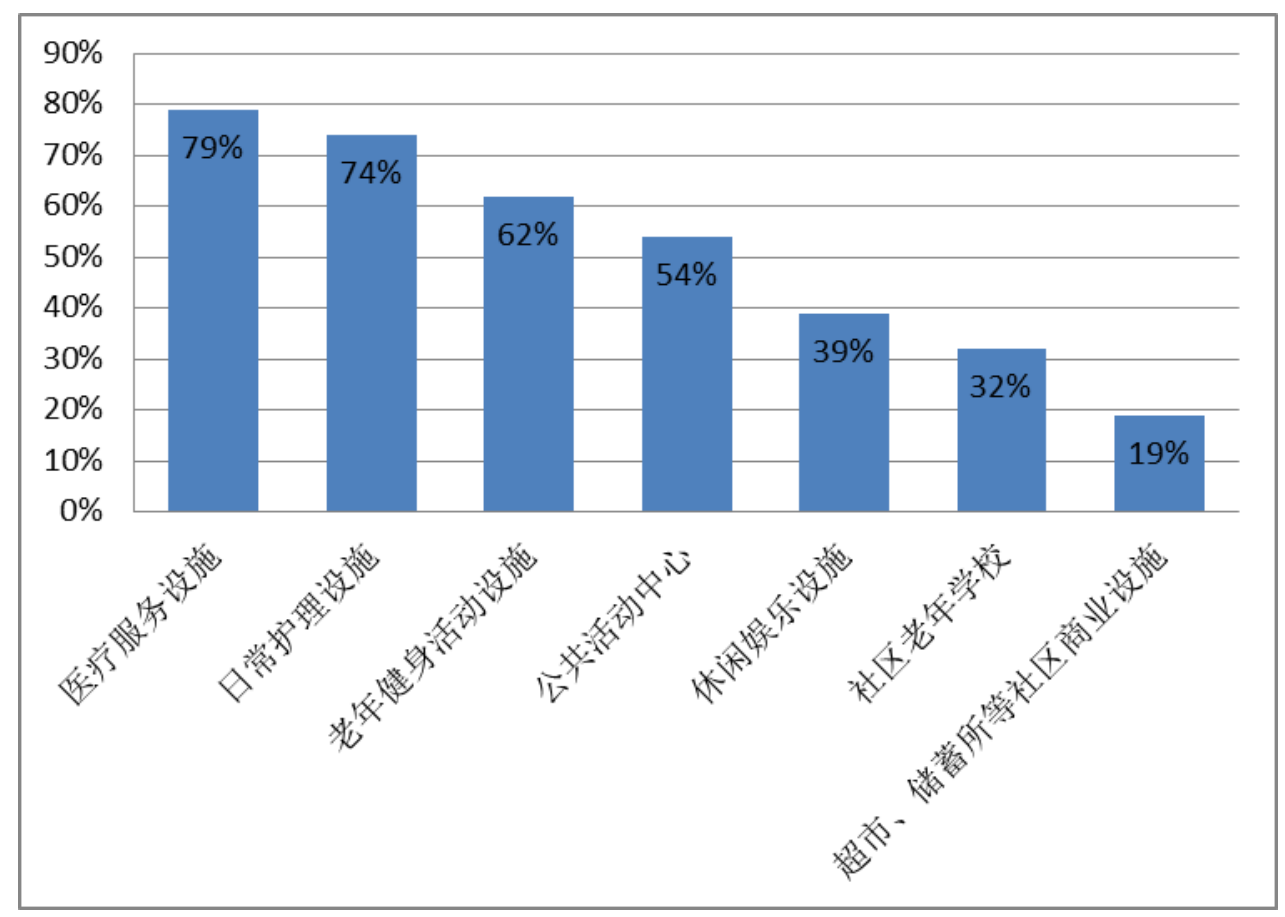

图 3 老年人对社区服务设施需求情况

在问及 “如果在小区提供养老服务, 您每月能承担的费用是多少” 时, $43 \%$ 老人选择 $300 \sim 800$ 元每月, $26 \%$ 的老人选择 800 1200 元每月, 通过对老年人进行交流, 结合老年人的收入情况来看, 老年人能承受的 社区养老服务费用在收入的 $1 / 3^{\sim} 1 / 2$ 之间。

\section{3 基于传统养老文化的居住区养老设施规划构想}

结合我国的传统养老文化和前面的城市老年人养老调研结果, 可以看出, 家庭在养老方面起到了重要 的作用, 养老不能离开家庭环境, 人到老年仍然离不开自己的大家庭, 离不开原有熟悉的环境 ${ }^{[8]}$, 与子女 在一起居住或邻近子女居住是我国老年人的理想养老居住模式，也是符合我国传统养老文化的思想。以家 庭所在的社区为依托, 为家庭养老提供资源, 在普通居住社区中实现居住与养老一体化, 老年人既能得到 子女家庭的关怀，也能得到社区和社会的关怀与尊重， 
因此, 为了照顾到所有类别老年人的不同需求, 笔者提出的基于中国传统文化的居住区养老设施规划, 具体设想是以居住小区为基本单元，在居住小区内可由政府或者社会设立一定规模的供老年人生活起居、 活动娱乐、医疗康复一体化的老年服务设施，依据老年人的日常起居行动能力, 进行分级分类的日间照护 或全天照护，实现老人的居住与养老一体化 ${ }^{[9]}$ 。这样几乎所有的老年人可以依托原有的居住环境，一方面 保持原有的大家庭关系，与社区居民的邻里关系; 另一方面可以享受到家庭、社区邻里的照顾，也能在小 区所在的服务设施内生活与养老 ${ }^{[10]}$ 。这区别于现今盛行的单一性老年社区、老年公寓等。

\section{4 结语}

综合我国社会与家庭的传统价值观，以及我国家庭人口结构发展的趋势和城市建设等因素来考虑，依 托普通社区，做好居住小区的居住与养老一体化的养老设施的规划，使不同类别的老年人能够享受到全方 位的专业服务，同时能够得到家庭、社会、社区的实现家庭赡养与社会协助相结合的养老方式来解决老年 人的赡养问题是符合我国传统养老文化和经济发展需要的，对社会发展也有重大意义。

\section{5 致谢}

5.1 湖北省教育厅哲学社会科学研究重大项目（项目名称：老龄社会背景下的住区适老化通用设计研 究，项目编号：17D018）

5.2 湖北省教育厅人文社会科学研究项目（项目编号：14G111）

\section{Acknowledgement}

1. Major project of philosophy and social sciences research by Hubei education department(project name: general design research to adapt to the aged in the residential district under the aging society background, project number: 17D018)

2. Project of philosophy and social sciences research by Hubei education department (project number: 14G111)

\section{参考文献:}

[1] 陈莹. 论中国传统养老文化视角下机构养老理念的建构 [J]. 漳州师范学院学报（哲学社会科学版）, 2012,1 (84): 35-40.

[2] 陈建兰. 中国城市养老模式研究[D]. 南京: 南京大学, 2012

[3] 邓颖,李宁秀,刘朝杰等. 老年人养老模式选择的影响因素研究[J]. 中国公共卫生，2013,19（6)：731-732.

[4] 陶涛，从聪. 老年人养老方式选择的影响因素分析一一以北京市西城区为例[J]. 人口与经济，2014,3 (204)：15-22.

[5] 田园. 城市社区养老服务：日本的经验与启示[J]. 中国发展观察，2010,5：55-56

[6] 李科. 老年住区主体性生活空间设计研究[D]. 武汉：武汉理工大学，2010

[7] 俞卫, 刘柏惠. 我国老年照料服务体系构建及需求量预测[J], 人口学刊, 2012,4（194)：3-13.

[8] S Fallah-Fini, H Rahmad, HJ Chen et al. Connecting micro dynamics and population distributions in system dynamics models[J]. System Dynamics Review, 2013, 29(4):197-215.

[9] MJ Radzicki. System Dynamics and Its Contribution to Economics and Economic Modeling[J], Springer New York, 2011:727-737.

[10] L Gu, S Chen. A System Dynamics Approach to Human Resource Management[J], International Conference on Management \& Service, 2010(4):1-4 


\section{References}

[1] Chen ying: "Concept of constructing institution for aged under traditional Chinese cultural viewpoint" [J]. Journal of Zhang Zhou Normal University (Philosophy and Social Science Edition), Vol. 84(2012), No.1, p.35-40 (in Chinese)

[2] Chen Jian-lan: Research to endowment patterns of Chinese city [D]. (Nanjing: Nanjing University, China 2012), p.25-29.

[3] Deng Ying, Li Ning-xiu, Liu Chao-jie etc: "Research of influence factors to the choice of elderly endowment pattern" [J]. Journal of Public Health in China, Vol. 19(2013), No.6, p.731-732 (in Chinese)

[4] Tao Tao, Cong Cong: "analysis of influence factors to the choice of elderly endowment pattern - take Xicheng district of Beijing as an example" [J]. Journal of Population and Economy, Vol. 204(2014), No.3, p.15-22 (in Chinese)

[5] Tian yuan: "Urban community endowment services: Japan's experience and enlightenment"[J]. China's Development, Vol. 5(2010), p.55-56(in Chinese)

[6] li ke: Subjectivity research and design to elderly residential living space [D]. (Wuhan: Wuhan University of Technology, China 2010).

[7] Yu wei, Liu bai-hui: "Elderly care service system's construct and demand prediction in our country" [J], Journal of Population, Vol. 194(2012), No.4, p.3-13(in Chinese)

[8] S Fallah-Fini, H Rahmad, HJ Chen et al. Connecting micro dynamics and population distributions in system dynamics models [J]. System Dynamics Review, 2013, 29(4):197-215.

[9] MJ Radzicki. System Dynamics and Its Contribution to Economics and Economic Modeling [J], Springer New York, 2011:727-737.

[10]L Gu, S Chen. A System Dynamics Approach to Human Resource Management[J], International Conference on Management \& Service, 2010(4):1-4 